\title{
Systemic Treatment Approaches for Sporadic Desmoid-Type Fibromatosis: Scarce Evidence and Recommendations
}

\author{
Bernd Kasper \\ University of Heidelberg, Mannheim University Medical Center, Interdisciplinary Tumor Center, Sarcoma Unit, Mannheim, Germany
}

\section{Keywords}

Desmoid-type fibromatosis - Imatinib .

Systemic treatment · Patient advocacy groups

\section{Summary}

Desmoid-type fibromatosis (DF) is a rare disease characterized by a monoclonal, fibroblastic proliferation and a variable and often unpredictable clinical course. Although histologically benign, DF is locally invasive and associated with a high local recurrence rate, but lacks any metastatic potential. As there is no established or evidence-based treatment approach available as of today, an individualized treatment strategy is fundamental in the light of highly variable clinical presentations, anatomic locations, and biological behaviors. Surgery with negative margins has been the cornerstone of DF treatment; however, an overall reassessment of the management of DF patients has taken place in the last few years, and preservation of function and quality of life has become a priority in these patients. Evidence is scarce for systemic treatment; different pharmacological options can be proposed and will be reviewed here. To better define possible therapeutic strategies, a consensus approach has been initiated, bringing together sarcoma experts from the European Organisation for Research and Treatment of Cancer (EORTC) Soft Tissue and Bone Sarcoma Group (STBSG) with patient advocates from Sarcoma Patients EuroNet (SPAEN). As a prerequisite, patients should be discussed in a multidisciplinary setting in centers/networks with specific expertise and experience in this disease.

\section{Introduction}

Desmoid-type fibromatosis (DF) is a rare disease characterized by a monoclonal, fibroblastic proliferation and a variable and often unpredictable clinical course. It may affect nearly all parts of the body, often involving the extremities (including pelvic and shoulder girdles) and the trunk (mostly the abdominal wall), but may also occur in the abdominal cavity and the head-and-neck region. According to the current 2013 version of the World Health Organization classification, DF is defined as 'clonal fibroblastic proliferation that arises in the deep soft tissues and is characterized by infiltrative growth and a tendency toward local recurrence but an inability to metastasize' [1]. DF is a distinct rare tumor entity representing about $0.03 \%$ of all malignancies. In Germany, the number of patients being affected by sporadic DF each year is estimated at around 250-300 cases; however, no profound data is available until now. DF may occur between the ages of 15 and 60 years, with a characteristic peak at 30-35 years [2]. Most DFs occur sporadically; however, approximately $5-10 \%$ arise in the context of familial adenomatous polyposis with an incidence ranging from 3.5 to $32 \%$, with no gender predilection and a predominant abdominal localization [3]. Both types of DF should be clearly differentiated and the current review only covers the sporadic ones.

As there is no established or evidence-based DF treatment approach available as of today, a multidisciplinary and individualized therapeutic strategy is clearly required. From the time of initial diagnosis, DF patients should be referred to reference centers or networks; the management of patients (including biopsy) outside experienced centers or networks should be discouraged and the patients should be discussed within a multidisciplinary tumor conference. Due to the rarity and the long natural history of the disease, the level of evidence as it is available for more common tumor types is currently beyond reach for DF. Especially in the context of 
systemic treatment options, only a few phase II trials are available, and most published data arises from retrospective case reports or small series. There is no published phase III randomized clinical study on DF. The scarce evidence-based data of systemic DF treatment will be summarized in this review. Nevertheless, imatinib has been evaluated in 4 uncontrolled, prospective phase II trials - 1 national study under the coordination of the German Interdisciplinary Sarcoma Group (GISG) - showing promising results for progressive DF patients. There will be a focus on this systemic treatment option. Notably, a paradigm shift has taken place in the last few years regarding the overall treatment strategy for DF patients. Preservation of function and quality of life has become a priority in treatment decision-making. A stepwise approach to sporadic DF including an initial watch-and-wait strategy is currently agreed to be the most appropriate front-line approach [4]. With this background information in mind, a European joint effort was initiated based on the expertise of patients and professionals and has led to the development of consensus recommendations and a treatment algorithm for this complex patient group [5].

\section{Pathology and the Role of $\beta$-Catenin}

The diagnosis of a sporadic DF should be based on histology results gained from a core needle biopsy. This biopsy confirming the DF diagnosis is mandatory and a definitive histology result should be awaited before undertaking any further steps. Given the rarity of this disease, the diagnosis of DF should be confirmed by an expert soft-tissue pathologist. Immunostaining for $\beta$-catenin with nuclear positivity is helpful in establishing the diagnosis (Fig. 1, online supplemental material at www.karger.com/?DOI= 381909). Mutations in the $\beta$-catenin gene are found in approximately $80 \%$ of sporadic DFs. Until now, performing mutational analysis of $\beta$-catenin is not part of the routine diagnostic work-up. However, as it may help to establish the specific DF diagnosis [6], it is strongly encouraged. Among the different $\beta$-catenin mutations, T41A and S45F are the most common ones with 50\% and $25 \%$, respectively. While 2 studies reported an increased risk of recurrence of DF with S45F mutation [7, 8], other analyses did not observe such a correlation $[9,10]$. Therefore, prospective data will have to elucidate if $\beta$-catenin mutational analysis might be used as a predictive marker and, hence, may be helpful in treatment decisionmaking.

\section{Treatment Options}

\section{Surgery}

Regarding surgical resection with negative margins - having been considered the standard of care for DF patients for many years - a paradigm shift has taken place over the last decade. Due to the heterogeneity and the variable and often unpredictable clinical courses, a more conservative and non-mutilating approach has been introduced into the DF treatment armamentarium. In con- trast to soft-tissue sarcomas where positive margins are a wellknown predictive factor for local failure [11], data regarding the possible prognostic significance of positive margins after DF excision is contradictory [12-14], leading to a reassessment of the overall management: Preservation of function and quality of life has become a priority in treatment decision-making. As stated before, the clinical course of DF can be very heterogeneous, varying between rapid progression and long periods of stabilization, or even occasional regression in $5-10 \%$ of the cases. Therefore, an initial observation period has been proposed by many investigators to further limit morbidity and avoid any functional deficit [15]. Such a front-line conservative approach seems appropriate as several retrospective series have shown progression-free survival rates of up to $50 \%$ at 5 years for patients managed with such a watch-andwait strategy [16]. This approach offers a way to understand the behavior of the disease and to tailor the next treatment steps. This strategy is currently agreed to be most appropriate as front-line approach, to minimize overtreatment and unnecessary morbidity in a subset of DF patients. No doubt, patients should be closely followed up according to the recommendations stated in the position paper [5] and, of course, this strategy has to be evaluated prospectively.

\section{Radiotherapy}

Asymptomatic DF patients should be carefully watched without active management, as suggested by the current 2014 version of the European Society for Medical Oncology (ESMO) clinical practice guidelines [17]. There is no indication for adjuvant radiotherapy in case of $\mathrm{R} 0$ resections. In the case of $\mathrm{R} 1$ or $\mathrm{R} 2$ resections, a re-resection should not be considered routinely and patients should be monitored preferentially. Postoperative radiotherapy may be an option for patients operated for recurrent disease, especially if the tumor was located at critical sites. However, it has to be considered that the average DF patient is young, with an anticipated normal life expectancy, and can therefore be subject to late radiation-induced morbidity including secondary malignancies. According to European Organisation for Research and Treatment of Cancer (EORTC) data, radiotherapy at a dose of 56 Gy in 28 daily fractions of $2 \mathrm{~Gy}$ has been shown to provide adequate local control in the majority of progressive patients, with a local control rate of $77 \%$ and a complete response rate of $17 \%$ [18]. There is no significant difference in local control between radiotherapy regimens above or below 56 Gy; however, there is a significant increase in late radiation-related morbidity above 56 Gy [19]. Therefore, the risk/benefit ratio has to be discussed individually with the patient.

\section{Systemic Treatment}

For clearly progressing cases, in non-resectable situations and in situations where an R0 resection would lead to functional impairment or deficit, non-surgical treatment modalities have to be evaluated. However, there is no standardized optimal treatment and the treatment modalities need to be individualized on a multidisciplinary basis. Different pharmacological options can be proposed, comprising anti-hormonal therapies such as tamoxifen, non-ste- 
roidal anti-inflammatory drugs (NSAIDs), low-dose chemotherapy such as methotrexate plus vinblastine, tyrosine kinase inhibitors such as imatinib or sorafenib, and full-dose chemotherapy using anthracycline-based regimens active in soft-tissue sarcomas, including liposomal doxorubicin. A systematic review analyzed the value of systemic treatment options used between 1970 and 2000 and came to the conclusion that only few phase II trials are available; most published data are from retrospective case series and there is no published phase III randomized clinical study on the systemic treatment of DF patients until today [20]. Most of the above-listed therapeutic options are used 'off-label' and are therefore not reimbursed in many European countries. Wherever possible, inclusion of patients in clinical trials is essential to better define the efficacy and indications of each of the treatment options.

There is no clear rationale for the frequently used anti-hormonal agents such as tamoxifen. They are used, alone or in combination with NSAIDs such as sulindac, as first-line medical treatment, mainly because of their limited toxicity, rare adverse events and low costs. However, there is only 1 prospective study in the pediatric patient population evaluating the combination of tamoxifen and sulindac, with relatively low activity measured by response rate and progression-free survival rate [21]. NSAIDs have documented influence on the $\beta$-catenin signal pathway. If administered, the response rate to anti-hormonal therapy is rather low and only observed after several months of treatment. Therefore, a general recommendation for its use could not be given in the position paper [5].

The chemotherapeutic option is reserved for those situations where the anatomic site is the critical issue, in the case of hormonal therapy failure, or for aggressively growing and/or symptomatic or even life-threatening DF. In the pediatric population, the combined administration of a 'low-dose' regimen of methotrexate and vinblastine demonstrated a response rate of $19 \%$ in a cohort of 28 patients and could stabilize the DF in half of the patients for a median duration of 9 months [22]. The usually intended time of administration of at least 1 year may lead to toxicity and subsequent problems in compliance especially in the adult population. Moreover, there is no prospective data for this combination in adults. A randomized trial evaluating pazopanib versus chemotherapy with methotrexate plus vinblastine is ongoing in France in centers of the French Sarcoma Group (NCT01876082). Full-dose chemotherapy using anthracycline-based regimens similar to soft-tissue sarcoma treatment is characterized by a higher response rate [23]. Anthracyclines are usually administered for 6-8 cycles. Pegylated liposomal doxorubicin has been reported in uncontrolled patient series from single centers to have significant activity with acceptable toxicity and, importantly, less cardiac toxicity than conventional doxorubicin [24]. It is therefore considered as the treatment of choice by many investigators. However, the recommended dose of $50 \mathrm{mg} /$ $\mathrm{m}^{2}$ every 4 weeks is rather toxic, so that the use of lower doses is appropriate if the intention is to give it to a maximum response, which can take several months. It has been demonstrated that prolonged treatment may be unnecessary with liposomal doxorubicin, as a treatment duration of 6 months is effective and limits cumula- tive toxicity and risk [25]. Response to chemotherapy in terms of pain relief is usually rapid, while radiological tumor stabilization and shrinkage may occur at a later time point and continue for many months beyond treatment discontinuation.

There is prospective, uncontrolled (non-randomized, phase II) evidence for the activity of the tyrosine kinase inhibitor imatinib in patients with progressive DF, with high rates of stabilization of around $50-80 \%$, despite a rather low response rate ranging from $5-15 \%$, and with a favorable toxicity profile [26-28]. Altogether, 140 DF patients have been evaluated prospectively with this treatment option and the published literature is summarized in table 1. One of these phase II trials was initiated in Germany and conducted within the GISG, evaluating imatinib to induce progression arrest in 37 evaluable DF patients not amenable to surgical resection with R0 intent or accompanied by unacceptable function loss (NCT01137916). One major eligibility criterion was a histologically confirmed DF showing progressive disease according to the Response Evaluation Criteria in Solid Tumors (RECIST) 1.0 within 6 months before study inclusion. Patients were treated with an intended dose of $800 \mathrm{mg}$ imatinib daily over the period of 2 years. Study accrual started in July 2010 in 5 GISG centers and finalized in September 2013. The primary endpoint was the non-progression rate after 6 months of imatinib treatment. The final analysis for the primary endpoint - presented at the 2014 Annual Meeting of the ESMO - showed that 24 out of 37 evaluable patients were progression free at 6 months of imatinib treatment and therefore reached the primary endpoint. Response assessment after 6 months revealed 1 partial response (3\%) and 23 stable diseases (62\%). Out of the 13 patients counted as non-successors, 10 patients had documented disease progression (27\%); 1 patient terminated due to toxicity and there were 2 study withdrawals. Hence, with a $65 \%$ progression arrest rate at 6 months after start of treatment, imatinib clearly exceeded the primary endpoint in this GISG trial, encouraging further investigation of imatinib in this disease. Follow-up will continue until the end of the 2 years of intended treatment duration [29]. The selling points of the GISG study compared to the 3 previously published trials were the inclusion of patients with RECIST 1.0 progressive disease alone and the long treatment duration of 2 years (table 1). Looking at the treatment goal in the individual patient situation from a more differentiated point of view, imatinib reaches a response rate of maximally $10-15 \%$. So, if the focus is on prompt response, chemotherapy with an anthracycline-based regimen or liposomal doxorubicin should be preferred because of their higher response rates. In a retrospective cohort, the use of sorafenib revealed a slightly higher response rate $(25 \%)$ compared to imatinib and a disease stabilization rate of 70\% [30]; however, no prospective data is available yet. Currently, sorafenib is being tested in a phase III, randomized, double-blind, placebo-controlled setting in the USA (NCT02066181). A randomized trial (DESMOPAZ) evaluating pazopanib versus chemotherapy with methotrexate plus vinblastine is ongoing within the French Sarcoma Group (NCT01876082). Efforts are needed to make imatinib and other tyrosine kinase inhibitors accessible for advanced DF patients in countries where these drugs are not reimbursed. 
Table 1. Prospective trials with imatinib in DF patients $(\mathrm{n}=140)$

\begin{tabular}{|c|c|c|c|c|c|c|c|}
\hline & $\mathrm{n}$ & $\begin{array}{l}\text { Inclusion } \\
\text { criteria }\end{array}$ & $\begin{array}{l}\text { Treatment } \\
\text { dose, mg }\end{array}$ & $\begin{array}{l}\text { Treatment } \\
\text { duration }\end{array}$ & $\begin{array}{l}\text { Response } \\
\text { rate, \% }\end{array}$ & $\begin{array}{l}\text { 6-Month } \\
\text { PFS, \% }\end{array}$ & $\begin{array}{l}\text { 12-Month } \\
\text { PFS, \% }\end{array}$ \\
\hline $\begin{array}{l}\text { Heinrich et al. } 2006 \\
\text { [26] }\end{array}$ & 19 & $\begin{array}{l}\text { no PD required; } \\
\text { 'heavily pretreated } \\
\text { patients' }\end{array}$ & 800 & 325 days & 16 & 53 & 36.8 \\
\hline $\begin{array}{l}\text { Penel et al. } 2011 \\
\quad \text { [27] }\end{array}$ & 35 & $\begin{array}{l}\text { no RECIST PD; } \\
\text { 'radiological } \\
\text { evidence for PD' }\end{array}$ & 400 & 1 year & 11 & 80 & 67 \\
\hline $\begin{array}{l}\text { Chugh et al. } 2010 \\
\text { [28] }\end{array}$ & 49 & $\begin{array}{l}\text { no PD required; } \\
\text { 'locally advanced } \\
\text { disease' }\end{array}$ & $\begin{array}{l}200-600, \\
\text { BSA } \\
\text { adjusted }\end{array}$ & $\begin{array}{l}\text { until PD; } \\
9 \text { pts. } \\
>3 \text { years }\end{array}$ & 6 & 84 & 66 \\
\hline $\begin{array}{l}\text { Kasper et al. } 2014 \\
\text { [29] }\end{array}$ & 37 & $\begin{array}{l}\text { RECIST PD } \\
\text { required }\end{array}$ & 800 & 2 years & 3 & 65 & $\begin{array}{l}\text { not yet } \\
\text { reached }\end{array}$ \\
\hline
\end{tabular}

$\mathrm{BSA}=$ Body surface area, $\mathrm{PD}=$ progressive disease, $\mathrm{PFS}=$ progression-free survival, pts. = patients, RECIST $=$ Response Evaluation Criteria in Solid Tumors.

To evaluate the efficacy of the above-described targeted therapies such as imatinib, the use of positron emission tomography with 2-deoxy-2-[ $\left.{ }^{18} \mathrm{~F}\right]$-fluoro-D-glucose (FDG-PET) has been proposed. $22 \mathrm{DF}$ patients were analyzed using FDG-PET before imatinib treatment initiation and 4-6 weeks after start of treatment. A median decrease in the standardized uptake value (SUV) of $30 \%$ could be demonstrated and no patient showed an SUV increase [31]. Therefore, the authors suggested that PET may be used as a surrogate marker in order to predict the response to therapy early in the course of treatment and to help decide whether imatinib therapy should be continued [32, 33].

As stated above, a consensus initiative has been launched, bringing together sarcoma experts from the EORTC/Soft Tissue and Bone Sarcoma Group (STBSG) with patients and patient advocates from Sarcoma Patients EuroNet (SPAEN), and has led to the development of consensus recommendations based on the patients' and professionals' expertise - for the first time ever in this disease. Regarding systemic treatment options, the position paper stated that ' (...), it is reasonable to employ the less toxic therapies before the more toxic ones in a stepwise fashion. However, due to the lack of randomized or comparative data, we are not in the situation to propose a definitive order of the existing systemic treatment options. Out of the variety of possible systemic treatment options, one can be chosen taking into account the dynamic growth of the tumour, the expected response rate, the planned treatment duration and the toxicity and possible side effects of the administered drug' [5]. To gain more evidence-based data in this rare disease, the conduction of randomized or comparative studies is highly encouraged. As described earlier, a paradigm shift in the overall management of DF patients has taken place during the last decade and preservation of function and avoiding cosmetic alterations have become a priority in the overall management strategy of DF patients. Therefore, it should always be considered that DF is a benign disease and that the patient's quality of life should be in the focus of treatment decision-making. Hence, it is recommended to offer patients psychological and social support and to collaborate with pain control specialists and physiotherapists [5].

\section{Online Supplemental Material}

Fig. 1. Typical fibroblastic spindle cell DF morphology with characteristic $\beta$-catenin immunostaining (1:200).

To access the supplemental material please refer to $w w w . k a r g e r . c o m / ? D O I=$ 381909 .

\section{Disclosure Statement}

B.K. has received honoraria from Novartis Pharma GmbH.

\section{References}

1 Fletcher CDM, Bridge JA, Hogendoorn P, Mertens F (eds): WHO Classification of Tumours of Soft Tissue and Bone (IARC WHO Classification of Tumours), ed 4. Lyon, IARC, 2013.

2 Kasper B, Stroebel P, Hohenberger P: Desmoid tumors - clinical features and treatment options for advanced disease. Oncologist 2011;16:682-693.

3 Wang WL, Nero C, Pappo A, Lev D, Lazar AJ, LópezTerrada D: CTNNB1 genotyping and APC screening in pediatric desmoid tumors: a proposed algorithm. Pediatr Dev Pathol 2012;15:361-367.
Gronchi A, Colombo C, Le Pechoux C, Dei Tos AP, Le Cesne A, Marrari A, Penel N, Grignani G, Blay JY, Casali PG, Stoeckle E, Gherlinzoni F, Meeus P, Mussi C, Gouin F, Duffaud F, Fiore M, Bonvalot S; ISG and FSG: Sporadic desmoid-type fibromatosis: a stepwise approach to a non-metastasising neoplasm - position paper from the Italian and French Sarcoma Group. Ann Oncol 2014;25:578-583.
Kasper B, Baumgarten C, Bonvalot S, Haas R, Haller F, Hohenberger P, Moreau G, van der Graaf WTA, Gronchi A; on behalf of the Desmoid Working Group: Management of sporadic desmoid-type fibromatosis: a European consensus approach based on patients' and professionals' expertise - a Sarcoma Patients EuroNet (SPAEN) and European Organisation for Research and Treatment of Cancer (EORTC)/Soft Tissue and Bone Sarcoma Group (STBSG) initiative. Eur J Cancer 2015; $51: 127-136$ 
6 Le Guellec S, Soubeyran I, Rochaix P, Filleron T, Neuville A, Hostein I, Coindre JM: CTNNB1 mutation analysis is a useful tool for the diagnosis of desmoid tumors: a study of 260 desmoid tumors and 191 potential morphologic mimics. Mol Pathol 2012;25:1551-1558.

7 Lazar AJ, Tuvin D, Hajibashi S, Habeeb S, Bolshakov S, Mayordomo-Aranda E, Warneke CL, Lopez-Terrada D, Pollock RE, Lev D: Specific mutations in the betacatenin gene (CTNNB1) correlate with local recurrence in sporadic desmoid tumors. Am J Pathol 2008; 173:1518-1527.

8 Colombo C, Miceli R, Lazar AJ, Perrone F, Pollock RE, Le Cesne A, Hartgrink HH, Cleton-Jansen AM, Domont J, Bovée JV, Bonvalot S, Lev D, Gronchi A: CTNNB1 $45 \mathrm{~F}$ mutation is a molecular prognosticator of increased postoperative primary desmoid tumor recurrence: an independent, multicenter validation study. Cancer 2013;119:3696-3702.

9 Dômont J, Salas S, Lacroix L, Brouste V, Saulnier P, Terrier P, Ranchère D, Neuville A, Leroux A, Guillou L, Sciot R, Collin F, Dufresne A, Blay JY, Le Cesne A, Coindre JM, Bonvalot S, Bénard J: High frequency of beta-catenin heterozygous mutations in extra-abdominal fibromatosis: a potential molecular tool for disease management. Br J Cancer 2010;102:1032-1036.

$\checkmark 10$ Mullen JT, DeLaney TF, Rosenberg AE, Le L, Iafrate AJ, Kobayashi W, Szymonifka J, Yeap BY, Chen YL, Harmon DC, Choy E, Yoon SS, Raskin KA, Hornicek FJ, Nielsen GP: $\beta$-Catenin mutation status and outcomes in sporadic desmoid tumors. Oncologist 2013; 18:1043-1049.

11 Gronchi A, Lo Vullo S, Colombo C, Collini P, Stacchiotti S, Mariani L, Fiore M, Casali PG: Extremity soft tissue sarcoma in a series of patients treated at a single institution: local control directly impacts survival. Ann Surg 2010;251:512-517.

12 Lev D, Kotilingam D, Wei C, Ballo MT, Zagars GK, Pisters PW, Lazar AA, Patel SR, Benjamin RS, Pollock RE: Optimizing treatment of desmoid tumors. J Clin Oncol 2007;25:1785-1791.

13 Salas S, Dufresne A, Bui B, Blay JY, Terrier P, Ranchere-Vince D, Bonvalot S, Stoeckle E, Guillou L, Le Cesne A, Oberlin O, Brouste V, Coindre JM: Prognostic factors influencing progression-free survival determined from a series of sporadic desmoid tumors: a wait-and-see policy according to tumor presentation. J Clin Oncol 2011;29:3553-3558.

14 Bonvalot S, Eldweny H, Haddad V, Rimareix F, Missenard G, Oberlin O, Vanel D, Terrier P, Blay JY, Le Cesne A, Le Péchoux C: Extra-abdominal primary fibromatosis: aggressive management could be avoided in a subgroup of patients. Eur J Surg Oncol 2008;34: 462-468.
15 Fiore M, Rimareix F, Mariani L, Domont J, Collini P, Le Péchoux C, Casali PG, Le Cesne A, Gronchi A, Bonvalot S: Desmoid-type fibromatosis: a front-line conservative approach to select patients for surgical treatment. Ann Surg Oncol 2009;16:2587-2593.

16 Briand S, Barbier O, Biau D, Bertrand-Vasseur A, Larousserie F, Anract P, Gouin F: Wait-and-see policy as a first-line management for extra-abdominal desmoid tumors. J Bone Joint Surg Am 2014;96:631-638.

17 ESMO/European Sarcoma Network Working Group: Soft tissue and visceral sarcomas: ESMO clinical practice guidelines for diagnosis, treatment and follow-up. Ann Oncol 2014;25(suppl 3):iii102-iiil12.

18 Keus RB, Nout RA, Blay JY, de Jong JM, Hennig I, Saran F, Hartmann JT, Sunyach MP, Gwyther SJ, Ouali M, Kirkpatrick A, Poortmans PM, Hogendoorn PC, van der Graaf WT: Results of a phase II pilot study of moderate dose radiotherapy for inoperable desmoid-type fibromatosis - an EORTC STBSG and ROG study (EORTC 62991-22998). Ann Oncol 2013;24:2672-2676.

19 Guadagnolo BA, Zagars GK, Ballo MT: Long-term outcomes for desmoid tumors treated with radiation therapy. Int J Radiat Oncol Biol Phys 2008;71:441-447.

20 Janinis J, Patriki M, Vini L, Aravantinos G, Whelan JS: The pharmacological treatment of aggressive fibromatosis: a systematic review. Ann Oncol 2003;14:181-190.

21 Skapek SX, Anderson JR, Hill DA, Henry D, Spunt SL, Meyer W, Kao S, Hoffer FA, Grier HE, Hawkins DS, Raney RB: Safety and efficacy of high-dose tamoxifen and sulindac for desmoid tumor in children: results of a Children's Oncology Group (COG) phase II study. Pediatr Blood Cancer 2013;60:1108-1112.

22 Skapek SX, Ferguson WS, Granowetter L, Devidas M, Perez-Atayde AR, Dehner LP, Hoffer FA, Speights R, Gebhardt MC, Dahl GV, Grier HE; Pediatric Oncology Group: Vinblastine and methotrexate for desmoid fibromatosis in children: results of a Pediatric Oncology Group phase II trial. J Clin Oncol 2007;25:501-506.

23 Garbay D, Le Cesne A, Penel N, Chevreau C, MarecBerard P, Blay JY, Debled M, Isambert N, Thyss A, Bompas E, Collard O, Salas S, Coindre JM, Bui B, Italiano A: Chemotherapy in patients with desmoid tumors: a study from the French Sarcoma Group (FSG). Ann Oncol 2012;23:182-186.

24 Constantinidou A, Jones RL, Scurr M, Al-Muderis O, Judson I: Pegylated liposomal doxorubicin, an effective, well-tolerated treatment for refractory aggressive fibromatosis. Eur J Cancer 2009;45:2930-2934.

25 Constantinidou A, Jones RL, Scurr M, Al-Muderis O, Judson I: Advanced aggressive fibromatosis: effective palliation with chemotherapy. Acta Oncol 2010;50: $455-461$.
6 Heinrich MC, McArthur GA, Demetri GD, Joensuu H, Bono P, Herrmann R, Hirte H, Cresta S, Koslin DB, Corless CL, Dirnhofer S, van Oosterom AT, Nikolova Z, Dimitrijevic S, Fletcher JA: Clinical and molecular studies of the effect of imatinib on advanced aggressive fibromatosis (desmoid tumour). J Clin Oncol 2006;24: 1195-1203.

27 Penel N, Le Cesne A, Bui BN, Perol D, Brain EG, RayCoquard I, Guillemet C, Chevreau C, Cupissol D, Chabaud S, Jimenez M, Duffaud F, Piperno-Neumann S, Mignot L, Blay JY: Imatinib for progressive and recurrent aggressive fibromatosis (desmoid tumors): an FNCLCC/French Sarcoma Group phase II trial with a long-term follow-up. Ann Oncol 2011;22:452-457.

28 Chugh R, Wathen JK, Patel SR, Maki RG, Meyers PA, Schuetze SM, Priebat DA, Thomas DG, Jacobson JA, Samuels BL, Benjamin RS, Baker LH; Sarcoma Alliance for Research through Collaboration (SARC): Efficacy of imatinib in aggressive fibromatosis: results of a phase II multicenter Sarcoma Alliance for Research through Collaboration (SARC) trial. Clin Cancer Res 2010;16:4884-4891.

29 Kasper B, Grünwald V, Reichardt P, Bauer S, Rauch G, Sommer M, Hohenberger P: Phase II study evaluating imatinib to induce progression arrest in RECIST progressive desmoid tumors not amenable to surgical resection with R0 intent or accompanied by unacceptable function loss - a study of the German Interdisciplinary Sarcoma Group (GISG). Ann Oncol 2014:25 (suppl 4):iv494.

30 Gounder MM, Lefkowitz RA, Keohan ML, D’Adamo DR, Hameed M, Antonescu CR, Singer S, Stout K, Ahn L, Maki RG: Activity of sorafenib against desmoid tumor/deep fibromatosis. Clin Cancer Res 2011;17: 4082-4090.

31 Kasper B, Dimitrakopoulou-Strauss A, Pilz LR, Strauss LG, Sachpekidis C, Hohenberger P: Positron emission tomography as a surrogate marker for evaluation of treatment response in patients with desmoid tumors under therapy with imatinib. Biomed Res Int 2013; 2013:article ID 389672.

32 Kasper B, Dimitrakopoulou-Strauss A, Strauss LG, Hohenberger P: Positron emission tomography in patients with aggressive fibromatosis/desmoid tumours undergoing therapy with imatinib. Eur J Nucl Med Mol Imaging 2010;37:1876-1882.

33 Dimitrakopoulou-Strauss A, Hohenberger P, Pan L, Kasper B, Roumia S, Strauss LG: Dynamic PET with FDG in patients with unresectable aggressive fibromatosis: regression-based parametric images and correlation to the FDG kinetics based on a 2-tissue compartment model. Clin Nucl Med 2012;37:943-948. 